\title{
Urbanização e fome: da gênese à popularização da situação alimentar urbana em Campinas (São Paulo, Brasil)
}

\section{Urbanization and hunger: from genesis to popularization of urban food situation in Campinas (São Paulo, Brazil)}

\author{
Livia Cangiano Antipon 1 \\ Marcio Antonio Cataia ${ }^{2}$
}

\begin{abstract}
Resumo
A cidade de Campinas, no estado de São Paulo, Brasil, caracteriza-se historicamente pela pujança econômica - influenciada pelo capital agrário, imobiliário e financeiro em sua formação urbana - e pela escassez alimentícia de sua população de mais baixa renda. Destaca-se na reprodução de seu espaço urbano, como resultado do intenso processo de aburguesamento e da vivencia da fome, uma situação alimentar urbana, que sinaliza para uma presença maciça de instituições alimentares, cujo fim seria, além de garantir a alimentação ao trabalhador, amenizar o mal da escassez e carestia de gêneros alimentícios de primeira necessidade na urbe. Baseados em pesquisa bibliográfica, documental e empírica, destacase que no período entre 1850 e 2016, Campinas viveu importantes transformações urbanas que modificaram suas práticas alimentares. Observa-se que a fome na população pobre campineira tem raízes na racionalidade urbana, contexto no qual o espraiamento das periferias estimulou ainda mais o crescimento e popularização de um mercado de refeições prontas e baratas no núcleo central - abrigo histórico de trabalhadores precarizados, os famintos do mundo urbano campineiro.

Palavras-chave:Comércio popular de alimentação. História de Campinas. Núcleo central.
\end{abstract}

\begin{abstract}
Campinas city in São Paulo, Brazil, is characterized by both a history of economic boon - influenced by agrarian, financial and real estate capital and food scarcity among its low-income population. As a result of an intense process of embourgoisement and the existence of hunger, highlighted in the reproduction of urban space is an urban food situation that is characterized by a large presence of food establishments that serve to provide food for workers, decrease food scarcity and prevent the inflation staple food prices. Drawing on secondary research as well as empirical data, we demonstrate that Campinas experienced important urban transformations that modified food practices in the period between 1850 to 2016. Hunger among the poor population of Campinas is rooted in
\end{abstract}

\footnotetext{
${ }^{1}$ Universidade Estadual de Campinas, Campinas. São Paulo. Brasil. liviacangiano@gmail.com.

${ }^{2}$ Universidade Estadual de Campinas. Campinas. São Paulo. Brasil. cataia@unicamp.br

Artigo recebido em: 05/06/2018. Aceito para publicação em: 18/04/2019.
} 
the rationalization of urban space consisting of peripheral sprawl and the growth and densification of markets of cheap prepared foods in the city center- serving to prevent famine among the precariat working classes, the hungry masses of Campinas' urban world.

Key words: Popular food commerce. Campina's history. City center.

\section{Introdução}

Este artigo objetiva expor o processo de surgimento, adensamento e popularização do que se reconhece por situação alimentar urbana no núcleo central da cidade de Campinas/SP.

Para tanto, aborda historicamente a formação da cidade evidenciando a abundância, representada pela pujança econômica da cidade, e a escassez, vivenciada pelos habitantes pobres da urbe, materializada no fenômeno mais degradante da miséria humana, a fome.

Resultante desse par dialético e reveladora da maneira pela qual a população pobre campineira se organizou nos interstícios do tecido urbano para a garantia de sua existência, tem-se, o que denominamos de situação alimentar urbana: uma presença maciça de instituições alimentares, como os mercados de alimentos, os restaurantes, os bares, as barraquinhas de comidas em lugares movimentados, os quiosques, entre outros, cujo fim seria, além de garantir a alimentação ao trabalhador que se desvinculava de seu lar, amenizar o mal que sofria em grande medida os pobres da urbe (MARTINS, 2010) - a escassez e a carestia de gêneros alimentícios de primeira necessidade.

Destaca-se no artigo o interim entre 1850 e 2016, período no qual a cidade de Campinas vive uma série de transformações urbanas que interferem e modificam as práticas alimentares, possibilitando a gênese, o adensamento e a popularização de sua situação alimentar urbana.

É nesse momento em que os mercados de alimentos, bem como o chamado "abastecimento alternativo" permitiram a formação da 
centralidade no meio urbano de Campinas e foram os responsáveis pela organização e controle das vendas de alimentos para os trabalhadores na cidade.

A metodologia de trabalho consistiu no levantamento bibliográfico documental - livros, teses, dissertações, artigos de periódicos, artigos de jornais, material fotográfico, séries e mapas históricos - em acervos consultados digitalmente e em espaços de conservação da memória em Campinas.

A ferramenta de método da periodização - divisão da noção de tempo em períodos (SANTOS, 1994) - apresenta-se como um caminho fundamental desta reflexão: foi capaz de traduzir a forma como a cidade - esse verdadeiro espaço-tempo (SANTOS, 1994) - foi produzida e planejada, além de revelar como os seus trabalhadores se organizavam em um cotidiano fortemente marcado pela fome - situação que se conserva até os dias atuais. Nesse sentido, de 1850 a 2016, se reconhecem três períodos, base para a estruturação do presente artigo: de 1850 a 1908, onde se encontra a gênese do mercado de alimentos da cidade; de 1909 a 1930, período de adensamento do mercado de alimentos; 1931 a 2016, momento de popularização desse mercado.

Conforme Santos (1994), nos estudos sobre o urbano carecem questionamentos sobre a formação histórica das cidades. Assim, a fundamental compreensão dessas formas do passado, exige, obrigatoriamente, a articulação com o conceito de espaço - o "resultado da inseparabilidade entre sistemas de objetos e sistemas de ações" sendo a sua natureza formada, de um lado, "pelo resultado material acumulado das ações humanas através do tempo, e, de outro lado, animado pelas ações atuais que lhe atribuem um dinamismo e uma funcionalidade" (SANTOS, 1996, p. 100-106). Tratando-se o espaço de "uma categoria histórica" (SANTOS, 1994, p. 67), o estudo da cidade não pode se desarticular do estudo do tempo. 
Logo, cabe afirmar que para um real avanço na compreensão do fenômeno da fome em Campinas e das práticas alimentares de seus trabalhadores, faz-se necessário um olhar sobre as formas e conteúdo da pobreza no processo de urbanização e nos distintos usos do território, já realizados nos interstícios da cidade.

Dessa maneira, há certos questionamentos sobre a maneira pela qual historicamente a cidade se transformou e se organizou nos últimos séculos: quando o pobre e o faminto tiveram os seus reais direitos e necessidades atendidas na cidade enriquecida pelo café? Em que medida o abastecimento alimentar alternativo - símbolo histórico de luta e resistência na urbe perde espaço em uma cidade transformada cada vez mais em mercadoria? Como a escassez de alimentos, inerente ao processo de empobrecimento da cidade, historicamente estrutura e sustenta o discurso da normatização burguesa dos espaços de sua comercialização?

Gênese da situação alimentar urbana campineira: a formação do mercado de alimentos na cidade (1850-1908)

A partir da metade do século XIX, ocorre o mais sensível desenvolvimento urbano de Campinas (GEIGER, 1963): a produção cafeeira modificou o rumo da cidade. Entre 1850 e 1908, destaca-se (i) a crise de escassez que se aprofunda com a transformação da urbe e (ii) o aburguesamento da cidade do café com o surgimento de mercados urbanos de alimentos e de outros estabelecimentos encarregados de comercializar os víveres na cidade (MARTINS, 2010).

Por um lado, Campinas foi a cidade de ricos barões do café, mas por outro, a cidade dos pobres trabalhadores. Tem-se como exemplos, o acirramento do contraste entre a miséria e a riqueza, com o deslocamento e confinamento espacial dos pobres da cidade e, também, a normatização da 
vida urbana, que acabou por modificar e aumentar a demanda por alimentos obtidos através do comércio, principalmente para atender o grande contingente populacional de migrantes que chegavam na cidade para compor a classe trabalhadora (LAPA, 2008a).

Entre outras funções, a normatização da vida urbana tinha como interesse a superação da crise de abastecimento alimentar - resultante do alto preço dos gêneros de primeira necessidade em razão da monocultura cafeeira. A riqueza abundante advinda do café produziu na cidade talvez a máxima manifestação da pobreza: a fome - a qual se apresenta como um fato histórico e associa-se intimamente ao modo de produção capitalista.

Foi nesse contexto de grandes disparidades, aqui evidenciadas no acesso à comida, que a ordem burguesa instalou-se e afirmou-se ao impor uma série de transformações urbanas e sociais. Destaca-se,o surgimento, em 1859, do primeiro mercado de abastecimento de alimentos de Campinas, marca de uma nova organização no controle e na circulação de homens e mercadorias (MARTINS, 2010).

De fato, a garantia de abastecimento alimentar da população campineira foi propulsora de uma reorganização do espaço urbano: as transformações transcendiam a função exclusiva do então chamado Mercado Grande de apenas comercializar alimentos ou combater a escassez de víveres de primeira necessidade. As novas delimitações e organizações do espaço também permitiram que o Mercado fosse um dos responsáveis pela formação de uma nova centralidade na Campinas do século XIX. Paralelamente, outros dois mercados reforçaram essa centralidade: o Mercado das Hortaliças de 1872 - o Mercadinho - e o Mercado das Hortaliças de 1886; ambos materializavam cada vez mais a transformação urbana da cidade que atraia mão de obra e investimentos.

A construção desses mercados marcou o início do processo de transformação da cidade, notavelmente informal e regida pelos costumes, em um espaço ordenado por um regulamento próprio - um lugar da norma. 
Paralelamente, era constituído um comércio organizado nas ruas de maneira "informal", ou como um abastecimento alternativo, possuindo importância fundamental para a cidade, principalmente para os seus sujeitos mais pobres.

Esse abastecimento alternativo era formado por armazéns dispersos pelos bairros, quiosques encontrados no centro da cidade, restaurantes humildes ou abastados, botequins, padarias, açougues, casas importadoras e de pasto, confeitarias, comércio de frutas, verduras, quitandas, a chamada cozinha econômica, na qual eram servidos pratos a preços mais acessíveis (MARTINS, 2010), e a miríade de ambulantes que perambulavam pelas ruas de Campinas.

Tais comércios eram Caracterizados pela mobilidade e autonomia de seus participantes e articulavam-se, em sua maioria, por uma vasta legião de pessoas pobres - imigrantes, escravos, negros livres e libertos - os quais se organizavam em trabalhos por conta própria.

Dessa maneira, na tentativa de "ganhar a vida", os "donos das ruas" tal como eram conhecidos os miseráveis de Campinas- circulavam por toda a cidade vendendo variados gêneros alimentícios em seus tabuleiros, carrinhos de mãoe carroças, levando "sons, cores, sabores e aromas que ajudavam a movimentar e temperar o dia a dia" (MARTINS, 2010, p. 241). Assim, alimentavam os pobres campineiros, que, em sua maioria, eram trabalhadores dependentes de um circuito de alimentação mais barato. Observa-se, de tal modo, os traços de um circuito popular de alimentação que funcionava como abrigo dos excluídos e marginalizados, representando, portanto, uma possibilidade de resistência na cidade, a qual, já em sua gênese, apresentava-se desigual.

Penteado (2012) afirma a existência de uma "urbanização sanitarista campineira" entre os anos de 1889 e 1908: consolidação da centralização normativa da venda de alimentos, que identificava o comércio ambulante como um estorvo à livre circulação e como um problema para a salubridade 
da cidade e para a saúde das pessoas. Essa imposição de um planejamento higienista acabou por traduzir a histórica maneira parcial de concepção da urbe campineira: aquela que busca transformar o seu espaço invisibilizando os seus sujeitos sociais pobres.

Nesse período de fortes embates entre a normatização e a informalidade na venda dos alimentos, a fome persistia em uma cidade que aprofundava o atendimento à ordem econômica vigente: "economia voltada para a produção extensiva e em larga escala, de matérias-primas e gêneros tropicais destinados à exportação" (PRADO JR., 1945, p. 207).

Apesar de o país presenciar um forte crescimento econômico, resultado dessas exportações, especialmente no estado de São Paulo, a epidemia de febre amarela em Campinas - que abateu a cidade nos anos de 1889, 1890, 1892, 1896 e 1897 - agravou a carência de alimentos (LAPA, 2008b; MARTINS, 2010). Apenas ficaram na cidade os famintos que não puderam fugir: a epidemia tornou visível ainda mais o problema da fome. Diversas atividades populares ligadas à venda de alimentos foram extintas ou fechadas, principalmente devido à impossibilidade de a cidade ser abastecida, uma vez que os produtores rurais não realizavam a entrega dos alimentos por medo da peste (MARTINS, 2010). Ou seja, o comércio ambulante e os restantes estabelecimentos alimentícios que proporcionavam o acesso à comida a um baixo custo pelas ruas de Campinas, ao encerrarem suas atividades, deixaram à mercê a parcela da população urbana mais pobre e necessitada.

No período estava posta a pior crise de abastecimento alimentar da cidade e, a fim de obter um maior controle sobre a sociedade e garantir a higiene de seu espaço, as grandes intervenções para a recuperação da cidade (BAENINGER, 1992; SANTOS, 2002; LAPA, 2008a, 2008b; MARTINS, 2010, PENTEADO, 2012).

De caráter higienista, a recuperação da urbe, devastada pela fome e afebre amarela, ocorreu ao longo da década de noventa do século XIX. O 
período epidêmico, portanto, manifestou-se de muitas formas na cidade, mas, primordialmente evidenciou-se na pior crise alimentar e urbana de Campinas, a qual se fez "sentir no reordenamento da organização e da ocupação do espaço, na disciplina da circulação, em novas orientações arquitetônicas e até mesmo nos comportamentos individuais e coletivos" (LAPA, 2008a, p. 266) da cidade. Assim, mais uma vez, a fome e o processo de urbanização caminharam juntos, marcando a história e o espaço campineiros.

O adensamento da situação alimentar urbana: do Mercadão de alimentos aos projetos de transformação no centro da urbe (1909-1930)

O período epidêmico agravou a crise de fome e motivou uma série de transformações urbanas de caráter higienista. A terceira epidemia de febre amarela (1892), por exemplo, acarretou por completo o fim das funções de abastecimento urbano no Mercado Grande, levando à sua extinção; já os Mercados de Hortaliças revelaram-se muito pequenos para a realização dessas vendas, colocando, mais uma vez, a necessidade de construção de um novo fixo para a comercialização de alimentos na cidade que voltava a crescer ao recuperar-se da febre e da fome.

Ainda que a garantia da existência de comida na urbe fosse de interesse público, a construção desse novo mercado foi regida pela iniciativa privada (MARTINS, 2010). Havia, portanto, na normatização do comércio de alimentação, uma visão de um negócio lucrativo, que trouxe consigo a perversidade mercantil em uma cidade onde grassava a fome - lógica que iria reger, também, outras transformações urbanas ao longo dos séculos XX e XXI.

A proposta inicial de construção do novo mercado foi realizada pelo empresário Luiz Nogueira, que planejava a construção do Mercado no Largo 
Correa Mello (arredores da atual Praça Carlos Gomes). A planta inicial do projeto excedia a área concedida para sua construção, mesmo assim obteve parecer favorável tanto da Comissão de Legislação da Câmara, quanto da Comissão de Higiene, Obras Públicas e Finanças (MARTINS, 2010).

Logo, para que fosse viável a construção de sua edificação, autorizouse uma série de desapropriações de terrenos e prédios - declarados de utilidade pública - ao redor do Largo Correa Mello (entre as ruas Benjamin Constant e Barreto Leme).

Obviamente, as desapropriações eram acompanhadas da valorização do entorno e dos potentes discursos de higienização do local, aprofundando, ainda mais, o aburguesamento da cidade. A Campinas higiênica anunciava: “O 'orgulho da cidade' não poderia ser rodeado por 'casinholas' que atentariam contra os mais elementares princípios da estética” (CIDADE DE CAMPINAS, N$^{o}$ 2.117, 14/4/1908 apud MARTINS, 2010, p. 348).

Além da concessão do novo espaço para a sua construção, o Mercadão - como é conhecido popularmente até os dias atuais - também obteve da Câmara Municipal a isenção de impostos municipais aos locatários das bancas e aos comerciantes ambulantes estacionados em seu espaço e a legitimação do monopólio do comércio em mercados de gêneros alimentícios em Campinas.

Conforme Martins (2010), com a inauguração do Mercadão, em 1908, outras medidas de "embelezamento" e "organização" ocorreram nas ruas centrais da cidade. Houve a implementação dos postes da Companhia Campineira de Iluminação e Força, os quais acabaram alterando tanto o movimento comercial da urbe quanto as próprias atividades das indústrias, trazendo um número de operários que dependeriam, cada vez mais, de uma alimentação garantida nas ruas.

Ocorreu, também, outra perspectiva ao abastecimento urbano - e consequentemente, ao próprio núcleo central de Campinas -: nasce com o mercadoa estrada de ferro Funilense, a qual comunicava o transporte de 
alimento entre o campo e o centro da cidade, configurando-o como um importante núcleo distribuidor (MARTINS, 2010) e tornando o centro de Campinas mais abrangente e dinâmico. A estrada de ferro teve papel fundamental nessa centralidade, pois os nexos ferroviárias da Funilense com a Paulista, a Mogiana e outras estradas de ferro regionais, autorizou o contato do Mercadão com várias cidades no interior de São Paulo, sul de Minas Gerais, Goiás e Matro Grosso.

As transformações urbanas em torno do Mercadão seguiram a tendência de um uso corporativo da cidade para que, cada vez mais, ela se tornasse fluída às materialidades, o que corroborava para tornar invisível ou distante do núcleo central - o que era considerado "não moderno".

Juntamente à construção do Mercadão, foi reiterado o caráter higienista das transformações urbanas. Nos anos seguintes, por exemplo, têm-se novamente em Campinas as obras coordenadas pelo engenheiro Sartunino de Brito. Dentre elas, fora inaugurada uma nova articulação viária, o canal-avenida-parque nomeado Avenida Orosimbo Maia importante avenida que até hoje abriga forte espessura comercial alimentícia. Configurando-se como uma construção perimetral, a avenida foi de extrema importância para a conexão do centro com os bairros próximos e para a própria circulação da cultura urbana na época (SANTOS, 2002).

É neste contexto de transformações urbanas, que visam tanto a garantia de abastecimento alimentício para a cidade que se ampliava, quanto amaior fluidez para a urbe, que a fase industrial de Campinas (Geiger, 1963) começaevidenciar-se. A chegada das indústrias em Campinas, que coincide com a crise cafeeira iniciada em 1929, andará paripassu com a maior inserção do capital imobiliário, principalmente em seu centro, o qual vivenciará suas maiores transformações.

Segundo Santos (2002, p. 278), o núcleo central de Campinas, nesse período, seria a representação - para a elite que sintetizava a ideologia urbanística dominante - da "antítese do progresso"; as ruas estreitas e 
construções arcaicas não comportavam as exigências das novas circulações de um centro regional, por isso, o centro começa a ser novamente transformado.

Embora este núcleo estivesse passando por uma série de modificações infraestruturais e de equipamentos urbanos, para atender majoritariamente as exigências urbanísticas da elite campineira - pós-fase epidêmica e de grave carência alimentícia -, muitas famílias das elites continuaram a abandoná-lo (SOMBINI, 2008), causando um movimento de ocupações - por parte dos trabalhadores, imigrantes e ex-escravos - de edificações vazias que viriam a formar os cortiços que perduraram no centro (LUCHIARI, 2006b apud SOMBINI, 2008). Assim se inicia o período que aludimos de popularização do núcleo central, com o adensamento de sua situação alimentar urbana.

Dos planos urbanísticos campineiros à popularização da situação alimentar urbana atual (1931-2016)

O adensamento da situação alimentar urbana ocorre em um contexto de maior fluidez do núcleo central da cidade - o qual iria se tornar pauta principal dos Planos Urbanísticos a partir dos 1930. Campinasse espraiará com os seus diferentes processos de remodelação e consequente periferização, fazendo necessária a concretização do ideal de uma integração fluida e rápida com o centro dentro dos projetos de modernização da urbe.

Tal espraiamento, como consequência da industrialização e dos planos de urbanização, é identificado por Geiger (1963, p. 257) por meio do surgimento de novos bairros em Campinas, como Bonfim, Ponte Preta, Guanabara, Parque Industrial e São Bernardo, entre outros, que compõem os trechos industriais da urbe. 
De fato, a nova configuração da cidade resultará dos nexos entre os Planos Urbanísticos do município de Campinas (PREFEITURA MUNICIPAL DE CAMPINAS, 2006), o processo de espraiamento e a periferização da população de baixa renda (CANO; BRANDÃO, 2002; BEGERES BISNETO, 2009; MESTRE, 2009; FONSECA, 2014). Essa relação evidencia, mais uma vez, um uso do território campineiro marcado fortemente por interesses corporativos e o "mecanismo da fragmentação e do empobrecimento das massas" (MESTRE; FONSECA, 2011, p. 33) no processo de urbanização desta cidade.

É nesse contexto, no período de 1934 a 1970, que o Plano de Melhoramentos Urbanos de Campinas - também conhecido como Plano Prestes Maia - é executado. Ainda de caráter funcionalista e higienista, tem como uma das principais propostas a primeira transformação radical do centro da cidade, substituindo o desenvolvimento reticulado ortogonal por uma intervenção urbanística radioconcêntrica (SANTOS, 2002).

O Plano abriu duas largas avenidas, a Francisco Glicério e a Campos Salles - hoje importantes vias populares as quais abrigam as principais espessuras do comércio popular de alimentação -, alargou algumas de suas principais vias, as avenidas Dr. Moraes Salles, Senador Saraiva e o viaduto Miguel Vicente Cury, além de demolir inúmeras construções antigas, como a Igreja do Rosário. Obedecendo às diretrizes traçadas internacionalmente na Carta de Atenas (1933), essas obras seguiam um padrão do urbanismo científico-técnico, o qual priorizava investimentos em obras de infraestrutura em detrimento de obras de embelezamento.

Segundo Fonseca (2014) - baseando-se nos estudos de Mestre (2009), Begeres Bisneto (2009) e Baeninger (1992) -, o município campineiro na década de 1950, devido à pavimentação da Rodovia Anhanguera (1948) e o consequente crescimento de loteamentos, é marcado pela ampliação do adensamento da ocupação das terras e pela instalação de indústrias mecânicas nas proximidades da rodovia. 
A antiga cidade do café foi modernizada sob a égide da indústria nos anos sessenta e setenta. Há nessa nova configuração a verticalização do núcleo central, em atendimento à "demanda crescente por moradias e, principalmente, por prédios comerciais" (JOLY, 2002, p. 34) - o que implicaria, certamente, em uma população de trabalhadores da cidade em sua histórica luta pela realização da restauração alimentícia fora da residência, cada vez mais distante do local de trabalho.

Campinas apresentou, entre 1960 e 1970, um dos maiores crescimentos populacionais do estado de São Paulo (ultrapassando os 5\% anuais), ocasionando o espraiamento de sua mancha urbana. Neste período, mais especificamente entre 1940 e 1960, que a valorização imobiliária das áreas centraisexpulsa boa parte da população pobre para as áreas menos valorizadas da cidade, constituindo, desse modo, uma das fases de sua periferização (FONSECA, 2014).

O aprofundamento da pobreza na cidade persistiu ao longo das décadas seguinte, igualmente reforçado por movimentos de reestruturação da urbe em consonância com a expansão dos investimentos imobiliários.

A década de 1970 foi caracterizada na cidade de Campinas pelo adensamento do meio técnico-científico-informacional (SANTOS, 1996), período em que o município inicia o seu processo de metropolização (CANO; BRANDÃO, 2002), o qual possibilitou que novas formas de organização do território implicassem em uma estruturação social complexa e desigual, permitindo a coexistência de atividades com diversos níveis de capital, tecnologia, organização e trabalho (SANTOS, 2008) - principal característica dos circuitos econômicos urbanos dessa região da cidade, presentes até os dias atuais.

Conjuntamente com esse processo, de 1971 a 1990, implementa-se na cidade o segundo plano de reestruturação: o Plano Preliminar de Desenvolvimento Integrado de Campinas (PPDI). Com ele, novos eixos viários foram remodelados e criados: "a rede rodoviária que perpassa a 
cidade é ampliada com a duplicação da Rodovia Anhanguera e a construção das Rodovias Dom Pedro I, Bandeirantes e Santos Dumont” (FONSECA, 2014, p. 37).

Os investimentos do período, tanto públicos quanto privados, - tais como os hipermercados, shoppings e condomínios fechados de alto padrão são empreendidos nesses eixos viários, então considerados como o "novo núcleo central" da cidade, reservando para o velho núcleo as atividades populares de comércios - sobretudo os de alimentação - e todo tipo de informalidade, geralmente destinadas às classes de menor poder aquisitivo (JOLY, 2002).

Ressalta-se que entre a década de setenta e oitenta, uma parte expressiva da população, não conseguindo despender parte de seus salários em habitações do mercado imobiliário formal, deslocou-se, novamente, para as áreas periféricas da cidade (FONSECA, 2014). Aumenta-se, assim, a população periférica e, consequentemente, a busca por um consumo dito popular no núcleo central: há uma necessidade cada vez maior de um circuito de refeições baratas para alimentar essa massa crescente de trabalhadores pobres.

Os mercados normatizados e alternativos que vendiam comida na cidade sempre acompanharam o crescimento da mesma e, sobretudo, condicionaram o próprio processo de urbanização. Portanto, a ampliação do espraiamento da urbe com suas respectivas fases de periferização, estimulou o crescimento de um mercado de refeições prontas - principalmente no núcleo central- já que, para muitos, a possibilidade de se alimentarem em suas residências, em uma cidade industrial, era - e continua sendo praticamente nula no período de trabalho.

A área, então, passa a concentrar ainda mais as atividades com baixa tecnologia, organização e capital - caso dos fixos e ambulantes que servem refeições prontas a um baixo custo. É o início de sua popularização e do fortalecimento do mercado alternativo de alimentos em suas ruas: em meio a 
tantas transformações urbanas, consolidou-se, assim, um mercado de refeições mais baratas no centro da cidade, configurando - até (e, sobretudo, nos) os dias atuais - a também popularização da situação alimentar urbana de Campinas.

Esse universo de comercialização popular de alimentos concentra-se, a partir de então, nas Avenidas Orosimbo Maia e Francisco Glicério, nas vias no entorno do Terminal Central e nas ruas Treze de Maio e Alvares Machado - lugares nos quais há o maior número de estabelecimentos alimentares do centro da cidade.

A popularização do mercado de alimentos nessas ruas resultou em um total aproximado de 100 estabelecimentos fixos, entre eles, bares e restaurantes. Em sua maioria, comercializam-se, bebidas em geral, e alimentos do tipo "rápido" como salgados fritos e assados, lanches, açaís e pastéis e os chamados "pratos feitos".

No que se refere aos "Serviços Ambulantes de Alimentação", a cidade de Campinas possui atualmente 342 estabelecimentos localizados em suas praças e calçadas. Ao todo são 93 bancas, 72 trailers, 149 quiosques e 28 bancas do tipo desmontável (ACIC- Associação Comercial e Industrial de Campinas). Tanto os trailers quanto as bancas desmontáveis servem como meios em que os sujeitos pobres conseguem viabilizar a sua permanência no centro da cidade, uma vez que esses "fixos" são os únicos possíveis de serem movimentados na urbe, permitindo, portanto, seu uso mesmo que não regularizado pelos órgãos municipais. Ou seja, ainda que "informais" - e por essa razão não tabulados pela SETEC (Serviços Técnicos Gerais de Campinas) -, esses estabelecimentos concentram-se no centro da cidade e possuem função fundamental para a restauração dos transeuntes da mesma.

A maior parte dos proprietários dos estabelecimentos fixos e dos vendedores ambulantes da alimentação afirma ser o centro o lugar propício para a existência e sobrevivência cotidiana da parcela pobre da cidade: a região, então, avulta-se como ponto de referência para (i) a possibilidade de 
realização do trabalho de uma parcela pobre em uma metrópole extremamente desigual; e (ii) o universo de trabalhadores que a circundam e dependem da mesma para a suas restaurações alimentares cotidianas.

Dessa maneira, configurada por uma rede popular de estabelecimentos alimentícios, a situação alimentar urbana possui papel fundamental na cidade ao ser formada e fortalecida pelo trabalho e consumo de cidadãos pobres que circundam e dinamizam o núcleo central. Esta, demarcada historicamente pela cooperação entre trabalhadores e consumidores e pelo conflito entre as demandas organizacionais da cidade, continua a abrigar os famintos do mundo urbano campineiro.

\section{Considerações Finais}

Faz parte da formação da cidade de Campinas a organização de um comércio de alimentos -através de um circuito alternativo e popular -, o qual é condição e resultado da pobreza estrutural (SANTOS, 2000) sob a qual se assenta a urbe desde a sua gênese.

A cidade, como exposto, apresenta uma configuração espacial marcada por intensa segregação, aspecto fundamental dos processos de desenvolvimento da formação socioespacial (SANTOS, 2008) brasileira, historicamente caracterizada por seletivas ondas de aburguesamento dos espaços urbanos.

Afirma-se, também, que a fome da população campineira tem raízes na racionalidade urbana. Considerada, assim, uma fome de fabricação humana (CASTRO, 1961); Isto, pois, se sobressai em Campinas a existência de uma pobreza urbana, ou melhor, "os aspectos da pobreza ligados diretamente à urbanização" (SANTOS, 1978, p. 78) uma vez que "o processo brasileiro de urbanização revela uma crescente associação com o da pobreza, 
cujo locus passa a ser, cada vez mais, a cidade, sobretudo a grande cidade" (SANTOS, 1993, p. 11).

Nossa reconstituição histórica começa com o período que vai do ano de 1850 até 1908, caracterizando a gênese da situação alimentar urbana em Campinas. Refere-se ao processo de acumulação do capital agrário e o início do crescimento contraditório da cidade, a qual de um lado materializou, em seu processo de urbanização, a pujança econômica e o seu aburguesamento identificados, por exemplo, na construção de três mercados urbanos de alimentos - e de outro, conviveu com parte de sua população mais pobre vivendo em um cotidiano de miséria e fome.

O final do período condiz com uma reflexão sobre a cidade devastada pela epidemia da Febre Amarela. A peste se junta à fome atingindo majoritariamente os pobres presos a urbe que vivencia a pior crise alimentar de sua história: as ausências de comércio, de gêneros alimentícios e de víveres caracterizaram o cotidiano campineiro em um processo de urbanização marcado fortemente pelo horror da carência alimentar.

Os dois últimos períodos, proposta que demarca quase a totalidade do século XX - de 1908 a 1990 -, tem como eventos geográficos principais a inauguração do quarto mercado urbano no centro da cidade, o popular "Mercadão", e a implementação dos Planos Urbanísticos, caracterizando um novo processo de urbanização em Campinas. Evidencia-se, durante esse momento, o aprofundamento das desigualdades socioespaciais da cidade, ao revelar a associação entre as inúmeras transformações urbanas de Campinas e o processo de periferização da mesma. Nesse momento, além de propor uma reflexão sobre a consolidação da pobreza estrutural, planejada e, portanto, histórica da cidade corporativa e fragmentada (SANTOS, 1990), a pesquisa permite uma análise do crescimento da articulação entre o centro da cidade e as suas periferias e apresenta, consequentemente, o adensamento e popularização da situação alimentar urbana campineira. 
Assim, o espraiamento da urbe com suas respectivas periferizações, estimulou o crescimento e popularização no núcleo central da cidade de um mercado de refeições prontas e baratas, uma vez que, para muitos, a possibilidade de realizarem suas restaurações alimentícias no lar, era - e continua sendo - praticamente nula.

Configurado por uma rede de bares e restaurantes populares e de ambulantes de alimentação, esse mercado, desde a sua gênese, adensamento e consolidação, é formado e fortalecido, sobretudo, pelo consumo dos trabalhadores precarizados que circundavam e dinamizavam - e ainda circundam e dinamizam - o núcleo central. Logo, a situação alimentar urbana,demarcada pela cooperação entre trabalhadores e consumidores e pelo conflito entre as demandas de aburguesamento da cidade, abriga, historicamente, os famintos do mundo urbano campineiro, demonstrando que as marcas do tempo permanecem no espaço geográfico.

\section{Referências}

BAENINGER, R. Espaço e tempo em Campinas: migrantes e expansão do pólo industrial Paulista. Dissertação (Mestrado em Sociologia), IFCH, UNICAMP, Campinas, 1992.

BEGERES BISNETO, V. Formação territorial e planejamento urbano: por um uso mais solidário do território de Campinas/SP. Dissertação (Mestrado em Geografia), FFLCH, USP, São Paulo, 2009.

CANO, W.; BRANDÃO, A. C. (coords.). A Região Metropolitana de Campinas urbanização, economia, finanças e meio ambiente. Campinas: Unicamp, 2002.

CARTA DE ATENAS. Cadernos de sociomuseologia, v. 15, n. 15, 1999.

CASTRO, J. Geopolítica da fome. Ensaios sobre os problemas de alimentação e de população no mundo. Rio de Janeiro: Editora da Casa do Estudante, 1961.

FONSECA, H. R. O recente processo de urbanização da cidade de Campinas- SP (1990-2014): as ocupações urbanas - um estudo dos usos do território da região Sul. Dissertação (Mestrado em Geografia). IG, Unicamp. Campinas, 2015.

GEIGER, P. A evolução da rede urbana. Rio de Janeiro: INEP, 1963.

IBGE. CENSO - Cadastro Nacional de Endereços para fins Estatísticos. 2010. Disponível em: http://www.censo2010.ibge.gov.br/cnefe/ Acesso em: 18, out, 2016.

JOLY, C. Refuncionalização e o patrimônio arquitetônico: o centro histórico de Campinas. Monografia (Graduação em Geografia), DGEO/IG, UNICAMP, Campinas, 2002.

LAPA, J. R., do A. A cidade: os cantos e os antros: Campinas 1850-1900. São Paulo: Editora da USP; Campinas: Editora da Unicamp, 2008a. 
Os excluídos: contribuição à história da pobreza no Brasil (1850-1930). São Paulo: Editora da USP; Campinas: Editora da Unicamp, 2008b.

MARTINS, V. Mercados urbanos, transformações na cidade: abastecimento e cotidiano em Campinas, 1859-1908. Campinas: Editora da Unicamp, 2010.

MESTRE, A. P. Os usos do território e as políticas urbanas: o Jardim Campo Belo no processo de fragmentação da cidade de Campinas. Dissertação (Mestrado em Geografia), IG, UNICAMP, Campinas, 2009.

MESTRE, A. P.; FONSECA, H. R. O Plano Diretor e a regionalização como ferramenta do planejamento de Campinas: uma análise da região do Jardim Campo Belo. Boletim Campineiro de Geografia, Campinas, v. 1, n. 1, p. 31- 46, 2011. http://agbcampinas.com.br/bcg/index.php/boletim-campineiro/article/view/21

PENTEADO, A. Urbanização e usos do território: as crianças e adolescentes e situação de rua na cidade de Campinas/SP. Dissertação (Mestrado em Geografia). Universidade Estadual de Campinas, Instituto de Geociências- IG, Unicamp, 2012.

PRADO JR., C. História Econômica do Brasil. São Paulo: Editora brasiliense, 1945.

PREFEITURA DE CAMPINAS. Histórico dos Planos Urbanísticos e Planos

Diretores de Campinas. Campinas, 2006.

http://www.campinas.sp.gov.br/governo/seplama/plano-diretor-2006/doc/historico.pdf

SANTOS, A. C. Campinas, das Origens ao Futuro: Compra e Venda de Terra e Água e um Tombamento na Primeira Sesmaria da Freguesia de Nossa Senhora da Conceição das Campinas do Mato Grosso de Jundiaí (1732-1992). Campinas-SP: Unicamp, 2002.

SANTOS, M. Pobreza Urbana. São Paulo: Edusp, 1978

Metrópole Corporativa Fragmentada: O caso de São Paulo. São Paulo: Hucitec, 1990.

A urbanização brasileira. São Paulo: Edusp, 1993.

Técnica, espaço, tempo. São Paulo: Edusp, 1994. 1996.

A natureza do espaço. Técnica e tempo, razão e emoção. São Paulo: Hucitec,

Por uma outra globalização. Rio de Janeiro: Record, 2000.

Da Totalidade ao Lugar. São Paulo: Edusp, $1^{a}$ edição, 2008.

SOMBINI, E. A. W. Habitação e projetos contemporâneos de refuncionalização de centros urbanos: o centro histórico de Campinas. Relatório final de Iniciação Científica, IG, Unicamp, 2008. 